\title{
Professional identity and social work
}

\author{
Stephen A. Webb (Ed.), 2017 \\ Routledge, Oxon, OX \\ ISBN 978-1-138-23443-7, pp. 246, paperback, NZD69.97
}

\begin{abstract}
$\mathrm{A}$ $s$ the first of its kind in the field of social work, this insightful book, Professional Identity and Social Work, is certainly worth a place on the front line of the bookshelf whether it belongs to students, educators, practitioners, academic researchers, or associated professionals. As a previous practitioner and currently a PhD student, having a sense of "being professional" is an important and influential issue that I have tried to find an answer to this during a period of my own education and even during a period of my own practice in social work. However, heretofore there has not been a book that has focused exclusively on the topic of professional identity in the field of social work. This might be because of the conceptual ambiguity and complexity that are entangled in the range of values, contexts, and institutional locations and social work's culture. The editor, Stephen A. Webb, whom many readers know from his often cited book, Social Work in a Risk Society (2006), successfully answers the complicated question of how practitioners come to have a sense of being a social worker, by incorporating a wide range of essential topics from 18 knowledgeable and practical contributors from around the world.
\end{abstract}

Why professional identity is becoming a "matter" in social work? (p. 3). The reason for its mattering is because professional identity affects not only how practitioners identify themselves, it also affects how practitioners are recognised by the out-group including other professions, service users, and the public. Moreover, the formation of professional identity in social work is closely connected with various concepts and issues such as work performance, credibility, commitment, resilience, and job satisfaction as well as recruitment and retention. As discussed in the introductory Chapter 1, the notion of professional identity is a contestable concept due to its changeable and dynamic nature. With the emergence of more integrated, multiprofessional organisational structures as well as rapidly paced economic and political changes, individual social workers experience multiple subject positions and shifts, and this adds a certain complexity to identifying what counts in the constitution of professional identity. In this regard, the meaning of professional identity can be somewhat different in different contexts as well as at different periods of time.

In responding to the request for social work to clarify its professional identity, the book comprises three, well-organised main sections. The first, Key concepts and perspectives, discusses the theoretical and conceptual matters that form around the issues of professional identity. There are four perceptive chapters in this section that provide a landscape that has to do with the key approaches and conceptual issues of professional identity as they relate to social work. For instance, Fran Wiles (Chapter 3) discusses the different ways of conceptualising the meaning of professional identity and highlights the importance of understanding the political and socio-economic nature of social work. Elizabeth Harlow (Chapter 5) exquisitely addresses the changed meaning of the social essential component of social work using a chronological approach and captures how the foundational concept of social provides a new understanding of professional identity in social work. 
The second section, Location, context and workplace culture, concentrates on the significance of institutional context and its location, and the centrality of the workplace culture in the treatment of professional identity. As the longest section, it covers a wide range of contexts in social work and workplace cultural issues: the contextual aspects of child welfare (Chapter 7, 8); health care (Chapter 9); residential social work (Chapter 12); and inter-professional partnerships (Chapter 10 ) in the consideration of the formation of professional identity; the significance of the concept of vocation (Chapter 6) and commitment (Chapter 11) in helping to shape one's professional identity as a social worker.

The third and final section, "Professional education, socialization and readiness for practice," focuses more directly on the formation of professional identity and the impact of social work education on professional socialisation. This section addresses the following question: how do students develop a sense of being professional through professional education and socialisation processes? To depict the dynamic transitional process involved in becoming a qualified practitioner, Julia Wheeler (Chapter 13) examines the significance of practice fieldwork placement as a professional socialisation and Maura Daly and Martin Kettle (Chapter 15) captures the fateful moments in the formation of professional identity in an educational context. Interestingly, Jadwiga Leigh (Chapter 14) explores the darker side of being professional as a process of forming a credible identity by using empathic or tactical deception. The editor concludes the discussion by critically synthesising the various chapters using the lens of matter of concern.

This book aims to reach an international audience. Although the contributors are from Anglophone countries and the discussion is based on a westernised intellectual map influenced by western political and socialeconomic backgrounds, I could reflect on my past experiences as a practitioner in South Korea through the lens of professional identity and this book has given me the precious insights I hoped to find. I am looking forward to finding out if this book will be translated into other languages so it can reach readers from non-Anglophone countries too.

\section{References}

Webb, S. A. (2006). Social work in a risk society: Social and political perspectives. New York, NY: Palgrave Macmillan. 